\title{
Improving averted loss estimates for better biodiversity outcomes from offset exchanges
}

\author{
Fleur J. F. Maseyk, Martine Maron, Ascelin Gordon \\ Joseph W. Bull and Megan C. Evans
}

\begin{abstract}
Biodiversity offsetting aims to achieve at least no net loss of biodiversity by fully compensating for residual development-induced biodiversity losses after the mitigation hierarchy (avoid, minimize, remediate) has been applied. Actions used to generate offsets can include securing site protection, or maintaining or enhancing the condition of targeted biodiversity at an offset site. Protection and maintenance actions aim to prevent future biodiversity loss, so such offsets are referred to as averted loss offsets. However, the benefits of such approaches can be highly uncertain and opaque, because assumptions about the change in likelihood of loss as a result of the offset action are often implicit. As a result, the gain generated by averting losses can be intentionally or inadvertently overestimated, leading to offset outcomes that are insufficient for achieving no net loss of biodiversity. We present a method and decision tree to guide consistent and credible estimation of the likelihood of biodiversity loss for a proposed offset site with and without protection, for use when calculating the amount of benefit associated with the protection component of averted loss offsets. In circumstances such as when a jurisdictional offset policy applies to most impacts, plausible estimates of averted loss can be very low. Averting further loss of biodiversity is desirable, and averted loss offsets can be a valid approach for generating tangible gains. However, overestimation of averted loss benefits poses a major risk to biodiversity.
\end{abstract}

Keywords Averted loss offsets, biodiversity offset, counterfactual scenario, habitat protection, mitigation, restoration

FLEUR J. F. MASEYK (Corresponding author, (D) orcid.org/0000-0002-2712-0438) The Catalyst Group, PO Box 1048, Wellington 6140, New Zealand E-mail fleur@thecatalystgroup.co.nz

MARTINE MARON* School of Earth and Environmental Science, The University of Queensland, Brisbane, Australia

Ascelin Gordon School of Global Urban and Social Studies, RMIT University, Melbourne, Australia

Joseph W. Bull Durrell Institute of Conservation and Ecology, School of Anthropology and Conservation, University of Kent, Canterbury, UK

Megan C. Evans $\$$ School of Earth and Environmental Science, The University of Queensland, Brisbane, Australia

${ }^{*}$ Also at: Centre for Biodiversity and Conservation Science, Faculty of Science, The University of Queensland, Brisbane, Australia

$\S$ Also at: Centre for Policy Futures, The University of Queensland, Brisbane, Australia

Received 4 September 2018. Revision requested 19 November 2018

Accepted 1 May 2019. First published online 10 February 2020.

\section{Introduction}

B iodiversity offset actions aim to generate biodiversity gains of adequate magnitude to counterbalance development-induced biodiversity losses. The goal is to achieve no net loss of biodiversity (IUCN, 2016). Best practice dictates that the use of offsets should only occur once all attempts to avoid, minimize or remediate biodiversity losses have been exhausted, in line with the mitigation hierarchy (Arlidge et al., 2018). Nevertheless, the use of biodiversity offsets has become increasingly common globally (Maron et al., 2016) and it is therefore critical that anticipated gains generated from offset actions are estimated as accurately as possible.

Many offset policies and projects rely wholly or partly on generating a gain by protecting existing biodiversity which, in the absence of the offset, is anticipated to be lost in the future. These are known as averted loss or avoided loss offsets. Processes resulting in the loss of biodiversity manifest in two general ways: (1) complete loss of area, such as that caused by deforestation or permanent draining of wetland habitat, and (2) loss of habitat condition (quality), as caused by impacts from factors such as surrounding land use, invasive species, climatic events and development-induced shifts in ecological processes that result in degradation. Thus, biodiversity area, biodiversity condition, or both, can be affected by threatening processes, and the loss of both can be averted to generate biodiversity gains within an offset exchange.

The loss of an area valuable for biodiversity is typically averted through actions that increase legal protection at a site (protection actions; Table 1), whereas averting loss of condition typically involves implementing management actions (maintenance actions; Table 1). Enhancement actions are often similar to maintenance actions, but rather than simply maintaining condition, they aim to improve the biodiversity at a site above its current value, or to shift an anticipated upward trajectory onto a steeper positive curve (Table 1). Relying solely on a single action (e.g. protection) is unlikely to generate gains sufficient to offset losses, either at the project or policy level (Maron et al., 2018). In practice, offset proposals often rely on a combination of offset actions aiming to preserve both the area (via protection actions) and the condition (via maintenance or enhancement actions) of a site to generate biodiversity benefits adequate to counterbalance losses. However, the anticipated gains from all proposed actions need to be estimated accurately, or the total 
TABLE 1 Categories of actions to achieve biodiversity gains within offset exchanges. Although protection, maintenance and enhancement actions can occur independently, they are often implemented together. Maintenance and enhancement actions can be similar, and both can occur at offset sites that have been protected.

\begin{tabular}{ll}
\hline Type of actions & Description \\
\hline Protection & $\begin{array}{l}\text { Designed to generate offset gains by avoiding or reducing the likelihood of the loss of extent (area) of biodiversity at a site; } \\
\text { typically achieved by changing the legal status of the land, or sea, to restrict use rights }\end{array}$ \\
Maintenance & $\begin{array}{l}\text { Designed to prevent declines in biodiversity condition \& thus maintain biodiversity in the condition it was at the start of } \\
\text { the offset activity; include actions targeted at specific processes affecting the condition of a site, or compromising species' } \\
\text { viability (e.g. exclusion of livestock causing habitat degradation, or control of invasive plant species) }\end{array}$ \\
Enhancement & $\begin{array}{l}\text { Aim to restore biodiversity values where declines have already occurred; designed to increase the condition of targeted } \\
\text { biodiversity above its condition at the start of the offset activity; similar to maintenance actions, but generally need to be } \\
\text { applied at greater intensity to reverse declines; may also include creation of biodiversity values in places where these have } \\
\text { been lost, such as through translocations of threatened species, or habitat creation }\end{array}$ \\
\hline
\end{tabular}

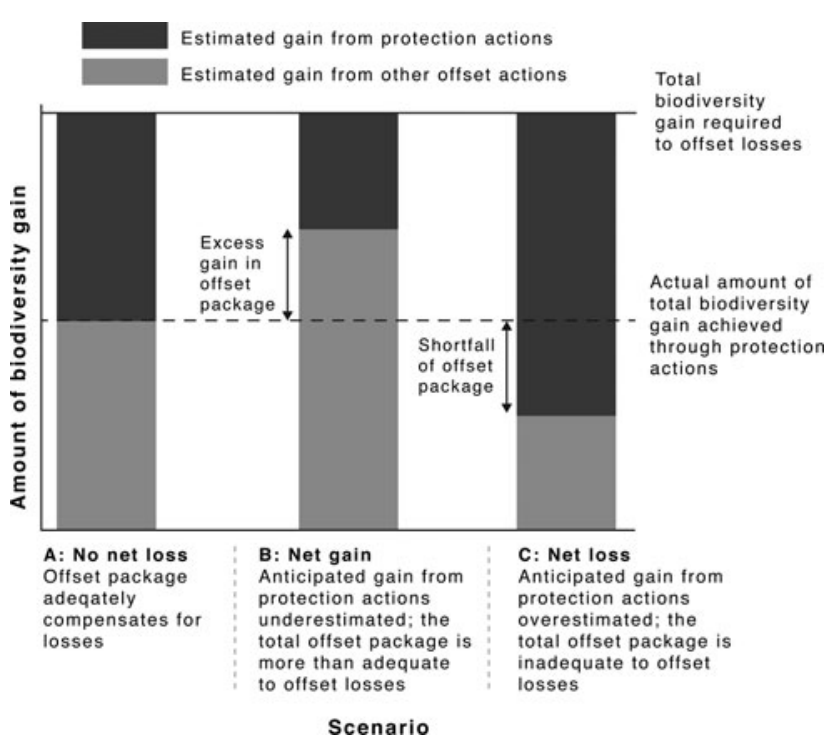

FIG. 1 A conceptual illustration comparing estimated biodiversity gain from offset actions with the actual biodiversity gain achieved from these actions, showing the influence of miscalculating gains from preventing loss of area (protection actions) on the adequacy of a total offset package. In this example, the offset package uses a combination of protection and other actions (e.g. maintenance or enhancement actions) in the offset design; with protection actions to prevent the loss of area being used as the primary action to achieve the offset, and other offset actions being used to supplement protection actions to reach the total biodiversity gain required to offset losses. In Scenario A (no net loss) the biodiversity gain is correctly estimated; the total offset package is adequate to balance losses. In Scenario B (net gain), the anticipated gain resulting from protection actions was underestimated and total gain delivered is more than expected; the total offset package is more than adequate to offset losses. In Scenario C (net loss), the anticipated gain from protection actions was overestimated meaning the other actions proposed to make up the balance of the total gain requirement were inadequate; total offset package is inadequate to balance losses.

offset package risks under-delivering biodiversity gains (Fig. 1).

Biodiversity gain can only be generated by averting loss if there is a genuine threat (not related to the original development project) that can be averted at the proposed offset site (Gordon et al., 2011; Maron et al., 2013). Identifying these threats and estimating the likelihood of them leading to the site being lost (likelihood of loss in the future) is essential for estimating the expected amount of averted loss secured by an offset proposal (Maron et al., 2013). However, this can be challenging because many offset policies lack explicit assumptions about counterfactual scenarios (i.e. the future situation in the absence of the offset action), empirical data to support estimation of the likelihood of loss, and guidance on how to use such data to construct plausible and robust scenarios of loss in the absence of the offset protection (Bull et al., 2015). Furthermore, lack of data to estimate likelihood of losses means having to rely on expert judgement in many cases, which is influenced by a range of cognitive biases. Where the likelihood of loss is overestimated this artificially inflates the perceived gain from protection, resulting in the offset exchange delivering insufficient actual gains to balance the losses (Maron et al., 2015).

Here, we present a method and decision tree to guide consistent and credible estimation of the amount of benefit generated by averting the loss of biodiversity at a proposed offset site. Firstly, we review high profile examples of existing approaches used in offset policies and projects internationally to estimate the amount of offset benefit generated by improving formal or legal protection of biodiversity. Secondly, we describe the calculation of the averted loss component of a biodiversity offset, and provide clear guidance for determining which additional drivers of biodiversity loss, in which situations, are appropriate to incorporate into estimates of future biodiversity loss. To reduce the influence of cognitive biases, we propose that estimates of likelihood of loss should be derived primarily from recent average background rates of loss, typically recent rates of loss at similar sites (i.e. sites in the same region, with comparable habitat or species assemblages, and subject to similar anthropogenic influences). To illustrate our method and decision tree, we focus specifically on averted loss of 
area, and thus 'likelihood of loss' refers to the probability of the complete loss of an area of biodiversity at some point in the future rather than degradation of its condition, unless explicitly stated. Nevertheless, a similar logic could also be adapted to estimate averted loss of condition. We conclude by describing some limitations of our approach and make recommendations for future research.

\section{Accounting for likelihood of loss in international offset policies and projects}

Any offset policy that allows offset benefits to be generated from protection of existing biodiversity assumes future biodiversity decline, in the presence or absence of the offset (Maron et al., 2015, 2018). These assumptions are frequently implicit and are sometimes captured in so-called multipliers (Bull et al., 2017). However, this can be problematic when the magnitude of the multiplier stipulated by offset policies implies implausibly high background rates of loss (Maron et al., 2015) or fails to account for factors such as time lags and uncertainty (Miller et al., 2015).

A wide range of approaches is currently used (with varying degrees of rigour) to estimate likelihood of loss under biodiversity offset policies and projects internationally (Table 2). Many biodiversity offset and related policies with no net loss goals assume ongoing background loss and thus allow gains to be generated by averting some of this loss (Maron et al., 2018), yet the rate of the assumed decline is often not explicitly described (Maron et al., 2013, 2015; Table 2).

For offset projects that elucidate their assumptions about the background rate of biodiversity loss, various methods may be used to derive these estimates including expert judgement, empirical data, or a combination. The offset proposal for the Rio Tinto QIT Madagascar Minerals ilmenite mine in the Anosy Region, Madagascar (Table 2) provides an illustrative example, wherein defensible future scenarios were informed by recent rates of biodiversity loss in the region, to evaluate the benefit of the offset actions (Temple et al., 2012). Another example is the offset strategy proposed for the Rio Tinto Oyu Tolgoi copper mine in the Southern Gobi Region, Mongolia, which included offset actions to reduce illegal hunting, improve rangeland management, strengthen protection and management of current protected areas, and improve the long-term security of tenure within the offset landscape (The Biodiversity Consultancy \& Fauna \& Flora International, 2012). In this offset strategy, strengthening tenure was proposed as a mechanism to prevent both loss of area (complete conversion of a site) and condition, and the amount of loss averted was based on expert judgement of anticipated future loss in the absence of protection.

Decision support tools and calculators can also be used to specify background rates of loss and estimate the amount of loss averted through protection actions on a case-by-case basis. For example, the guide used to calculate offset requirements under the Australian environmental offsets policy (Miller et al., 2015; Australian Government, 2018) explicitly requires a user-input estimation of the likelihood of loss (the risk-of-loss score), which is used to calculate the amount of loss averted through protection of the proposed offset site (Table 2). The Offsets Assessment Guide is applied on a project-by-project basis, but the risk of loss score is not dictated nor is a specific method prescribed for deriving it. This has resulted in inconsistencies in determining the offset actions required to counterbalance a given impact (Maseyk et al., 2017). In contrast, the biodiversity offset accounting system developed for the New Zealand Department of Conservation (Maseyk et al., 2016), which is a decision support tool independent of policy, explicitly adopts a static baseline, such that no biodiversity gain can be generated by averting future loss. This approach was adopted in recognition of the difficulty in making accurate predictions about future loss, and the high cost for biodiversity if these estimates are artificially inflated, but does not account for the benefits of protection where a genuine threat is averted. Using a static baseline is also a common approach in other jurisdictions, for example within the EU (Wende et al., 2018).

We suggest that the potential for overestimating averted loss, and thus the gain derived from securing protection of biodiversity area, is elevated when methods used to estimate likelihood of loss values are opaque, arbitrary, subject to bias, perception-based, and/or are inconsistent with jurisdictional offset requirements.

\section{Estimating gains from averted loss offsets}

Evaluating the amount of biodiversity benefit that is attributable to a specific action is critical for determining the amount of gain generated (Ferraro \& Pattanayak, 2006; Ferraro, 2009; Gibbons et al., 2016). This evaluation requires the description of two future scenarios: (1) the estimated biodiversity values at a specified time horizon after the action has been implemented (the with action scenario), and (2) the estimated biodiversity values in the absence of the action occurring (the without action scenario, also referred to as the counterfactual). The difference between the two scenarios determines the amount of biodiversity gain attributable to the specific offset action (Maron et al., 2013; Miller et al., 2015; Gibbons et al., 2016). When evaluating biodiversity offset proposals, it is critical that the size of the biodiversity gain resulting from an offset action is estimated based on plausible assumptions. Not achieving anticipated goals can be disappointing for any biodiversity project, but when the actions are tied to a goal of no net loss, any failures or shortfalls are potentially disastrous for biodiversity outcomes, as losses that have already occurred remain uncompensated and unaccounted for. The result of the 
TABLE 2 A sample of international offset policies, schemes, or decision support tools illustrating the varied approaches to estimating the likelihood of loss. Further detail is provided in other reviews on the use of multipliers (Bull et al., 2017) and no net loss policies (Maron et al., 2018).

\begin{tabular}{|c|c|c|c|}
\hline $\begin{array}{l}\text { Policy/scheme/project name } \\
\text { (Jurisdiction/location) }\end{array}$ & Type & $\begin{array}{l}\text { Generalized description of approach to } \\
\text { estimating threat of loss/or rate of value } \\
\text { accrued from an averted loss offset under } \\
\text { a counterfactual scenario }\end{array}$ & Source \\
\hline $\begin{array}{l}\text { Rio Tinto QMM ilmenite mine } \\
\text { (Anosy Region, Madagascar) }\end{array}$ & Project & $\begin{array}{l}\text { Used explicitly stated counterfactual scen- } \\
\text { arios that incorporated quantitative analysis } \\
\text { to estimate background annual rates of loss }\end{array}$ & Temple et al. (2012) \\
\hline $\begin{array}{l}\text { Rio Tinto Oyu Tolgoi copper } \\
\text { mine (Southern Gobi Region, } \\
\text { Mongolia) }\end{array}$ & Project & $\begin{array}{l}\text { Future likelihood of loss within proposed } \\
\text { offset site determined using expert evaluation } \\
\text { of likely pressures (as a result of poverty \& } \\
\text { increasing importance of mineral extraction } \\
\text { for economic development) }\end{array}$ & $\begin{array}{l}\text { The Biodiversity Consultancy } \\
\text { \& Fauna \& Flora } \\
\text { International (2012) }\end{array}$ \\
\hline $\begin{array}{l}\text { BioBanking Assessment } \\
\text { Methodology (New South } \\
\text { Wales, Australia) }\end{array}$ & State-level policy & $\begin{array}{l}\text { Uses a generic multiplier based on assump- } \\
\text { tions of high or low likelihood of decline } \\
\text { within a } 20 \text {-year time horizon. Assumptions } \\
\text { of high or low risk of decline are derived from } \\
\text { categorization of land based on land-use } \\
\text { zones }\end{array}$ & $\begin{array}{l}\text { The State of New South Wales } \\
\text { \& The Office of Environment } \\
\text { \& Heritage (2014) }\end{array}$ \\
\hline $\begin{array}{l}\text { Native Vegetation Permitted } \\
\text { Clearing Regulations (Victoria, } \\
\text { Australia) }\end{array}$ & State-level policy & $\begin{array}{l}\text { Assumes a likelihood of loss of vegetation } \\
\text { extent of } 10 \% \text { over } 10 \text { years (plus } 10 \% \text { for } \\
\text { prior management \& c. } 10 \% \text { for condition } \\
\text { maintenance) }\end{array}$ & $\begin{array}{l}\text { Department of Environment } \\
\text { Land Water \& Planning } \\
(2017)\end{array}$ \\
\hline $\begin{array}{l}\text { Queensland Environmental } \\
\text { Offsets Policy (Queensland, } \\
\text { Australia) }\end{array}$ & State-level policy & $\begin{array}{l}\text { Uses a generic ratio of exchange that impli- } \\
\text { citly assumes decline of condition \& area of } \\
18 \% \text { over } 20 \text { years, but does not explicitly } \\
\text { state the rate of decline }\end{array}$ & $\begin{array}{l}\text { The State of Queensland } \\
(2014)\end{array}$ \\
\hline $\begin{array}{l}\text { Environment Protection \& } \\
\text { Biodiversity Conservation Act } \\
\text { environmental offsets policy } \\
\text { (Australia) }\end{array}$ & Country-level policy & $\begin{array}{l}\text { Explicitly incorporates case-by-case risk of } \\
\text { loss estimates within the Offsets Assessment } \\
\text { Guide calculator. Guidance on good practice } \\
\text { for estimating risk of loss in the context of the } \\
\text { Environment Protection \& Biodiversity } \\
\text { Conservation Act offsets policy has recently } \\
\text { been produced }\end{array}$ & $\begin{array}{l}\text { Miller et al. (2015); Maseyk } \\
\text { et al. (2017) }\end{array}$ \\
\hline $\begin{array}{l}\text { Offsets for Loss of Biodiversity } \\
\text { (Colombia) }\end{array}$ & Country-level policy & $\begin{array}{l}\text { Assumes a decline in biodiversity but does } \\
\text { not specify the rate of this decline }\end{array}$ & Montenegro et al. (2012) \\
\hline $\begin{array}{l}\text { Biodiversity Offsets Accounting } \\
\text { Model (New Zealand) }\end{array}$ & $\begin{array}{l}\text { Policy independent } \\
\text { decision support } \\
\text { tool }\end{array}$ & $\begin{array}{l}\text { Explicitly assumes a static baseline (no } \\
\text { change in biodiversity value over time), thus } \\
\text { no net loss is compared to before the impact } \\
\text { \& not a counterfactual scenario. Users of the } \\
\text { model can implicitly incorporate rates of loss } \\
\text { into estimated future biodiversity values, } \\
\text { but the model gives no direction on how } \\
\text { to derive estimates of future loss }\end{array}$ & Maseyk et al. (2016) \\
\hline
\end{tabular}

error is permanent, uncompensated biodiversity loss, and hence averted loss offsets are a high-risk endeavour that require robust evaluation predicated on explicit, defensible assumptions.

Estimating the biodiversity gain secured by averting loss through protection of a site can be expressed as:

$$
G_{p}=\left(P_{w o}-P_{o}\right) \times A
$$

where $G_{p}$ is the gain from protection alone (the offset action), $P_{w o}$ is the probability of loss without the offset (from the counterfactual scenario) and $P_{o}$ is the probability of loss with the offset (from the offset scenario), and $A$ is the area of the offset site. If there is zero probability of loss once the offset is implemented, the gain becomes equal to the expected loss without the offset:

$$
G_{p}=P_{w o} \times A
$$

This equation assumes a relatively short time period (i.e. 5-50 years), because beyond this we can expect that the probabilities move towards becoming equal, and equally 
uncertain, as the ability to make defensible predictions decreases.

\section{Sources of error when estimating likelihood of loss}

There are three main sources of error when estimating the likelihood of loss:

Lack of explicit assumptions about counterfactual scenarios If an offset policy provides for averted loss offsets, there is an assumption that the counterfactual scenario is one of ongoing loss (Maron et al., 2015, 2018). However, as we have shown above, the estimated rate of this assumed loss is often not explicitly stated.

Failure to distinguish between drivers of loss that would trigger offset requirements and those that would not For the purpose of estimating likelihood of loss, impacts on biodiversity can be categorized into two types. Type I impacts are any impacts caused by an activity subject to legislative or policy controls that, following implementation of the mitigation hierarchy, require an offset, whereas type II impacts are all impacts resulting from activities that are not addressed by legislation or policy (Maron et al., 2018). When type I impacts are captured in probability of loss estimations $(P)$, the amount of benefit calculated is incorrectly claimed. This is because type I impacts are subject to policy controls meaning that losses would be avoided or offset, thus any loss of the site would have to be balanced elsewhere, so the gain in protecting a site from type I impacts is zero.

Cognitive biases These can occur as loss aversion bias, availability heuristic, and probability neglect bias. Loss aversion bias stems from a tendency of humans to be risk-averse, placing more emphasis on perceived losses than gains and focusing more on perceived consequence than likelihood of occurrence (Tversky \& Kahneman, 1974; Kahneman et al., 1991). Thus, concerns over the consequence of future biodiversity loss can unduly influence the estimates of the likelihood of this loss actually occurring when the stakes are high (e.g. when the site contains threatened taxa), because we wish to avoid the loss. The availability heuristic results from a tendency to make assessments based on the most recent information received (Tversky \& Kahneman, 1974; Kahneman et al., 1991). Therefore, if development has recently occurred in a similar area, it is plausible to overestimate the likelihood of loss at an offset site. The probability neglect bias occurs when uncertainty surrounding the likelihood of an anticipated event occurring in the future is high. A greater range of probabilities can appear plausible under such circumstances. Thus, when faced with the inherent uncertainty in decision-making that involves predictions, people have a tendency to disregard probability (Sunstein, 2003).

These errors, cognitive biases, and uncertainties can influence a decision-maker's ability to make an unbiased judgement of the likelihood of site loss, particularly when credible evidence is scarce. These factors often work in combination and typically result in an overestimation of the benefit of averted loss offsets. Recognizing this is challenging because in many cases protecting a site from future threats, by securing legal protection, is generally considered a positive outcome. It is counterintuitive to consider that such an action at the site or project scale may be detrimental at the policy or landscape scale.

For parties with a vested interest in minimizing the costs of meeting offset obligations, there is an incentive to overestimate the benefit of averted loss offsets (Gordon et al., 2015; Maron et al., 2016). The combination of cognitive biases, errors and asymmetric information provide considerable scope for the manipulation of likelihood of loss estimates, which can result in the selection of low-quality offset sites (Ferraro, 2008; Ruhl \& Salzman, 2011). Clear guidance is therefore needed to reduce such influences on likelihood of loss estimates.

\section{Improving transparency and credibility of estimates of future biodiversity loss}

To overcome the issues outlined above we propose an objective, robust, and repeatable process for calculating appropriate likelihood of loss estimates under both the offset $\left(P_{o}\right)$ and the counterfactual $\left(P_{w o}\right)$ scenarios. Our proposed method uses demonstrated past rates of loss to inform estimates of future likelihood of loss and is underpinned by five principles: (1) Recent past rates of loss in similar sites are usually a sound basis for predicting future rates of loss and should be used where available. (2) The likelihood of loss is site-specific but estimates should be informed by landscape-scale estimates. (3) Estimates of particularly high likelihood of loss at a site must be supported by credible and robust evidence. (4) The time horizon over which likelihood of loss is estimated, and thus the time over which benefit from averting loss is accrued, is clearly defined. (5) Type I impacts (those caused by activities that would be subject to legislative or policy controls requiring an offset) are excluded from likelihood of loss estimates.

These principles underpin our proposed method for estimating likelihood of loss under scenarios with and without offset action. The method is detailed below and illustrated in Fig. 2 (estimating likelihood of loss under a counterfactual scenario, $P_{w o}$ ) and Fig. 3 (estimating likelihood of loss under the offset scenario, $P_{o}$ ). 


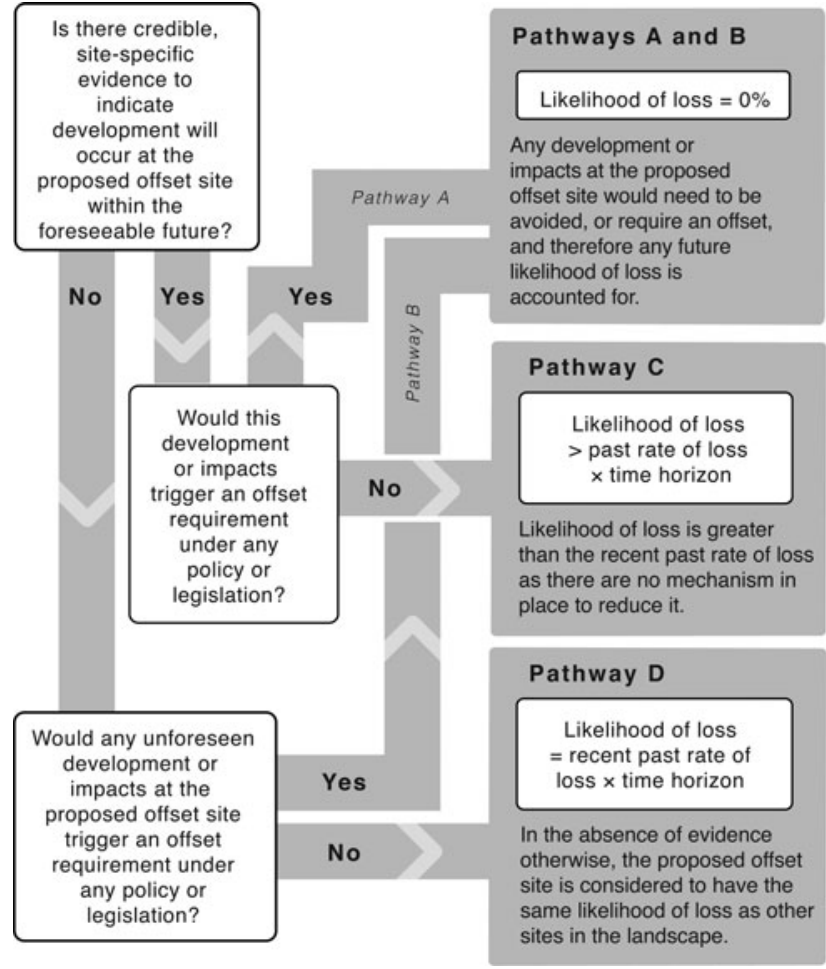

FIG. 2 A process for determining future likelihood of loss (total loss of area) under a counterfactual scenario $\left(P_{w o}\right)$. 'Foreseeable future' may be defined by the relevant policy or legislation but can be considered to be the life of the offset or a generation. The time horizon is the period over which the outcome of the offset is being calculated (e.g. benefit achieved at 20 years).

\section{Estimating likelihood of loss under a counterfactual scenario}

There are three important factors to guide estimation of the likelihood of loss of a proposed offset site under a counterfactual scenario: (1) site-specific influences on likelihood of loss, (2) policy and legislative requirements likely to be triggered by any impact to the site, and (3) recent rates of loss of similar sites. The four pathways in Fig. 2 help determine how these factors should guide estimates for both known and unknown type I and type II impacts.

Pathway A illustrates that even if the loss of a site is highly likely, but those losses result from type I impacts, the relevant likelihood of loss is negligible ( $0 \%$ in Fig. 2). Pathway $\mathrm{B}$ shows that without credible evidence for likely future development at a proposed offset site, and when any unanticipated losses would be type I impacts, the relevant likelihood of loss is also o\%. In both cases, this is because, assuming compliance with policy, any losses at the site would themselves have to be offset. Pathway $\mathrm{C}$ describes situations where development impacts would not be sufficient to trigger offset requirements, for example when the magnitude of the impact falls below a policy threshold that would

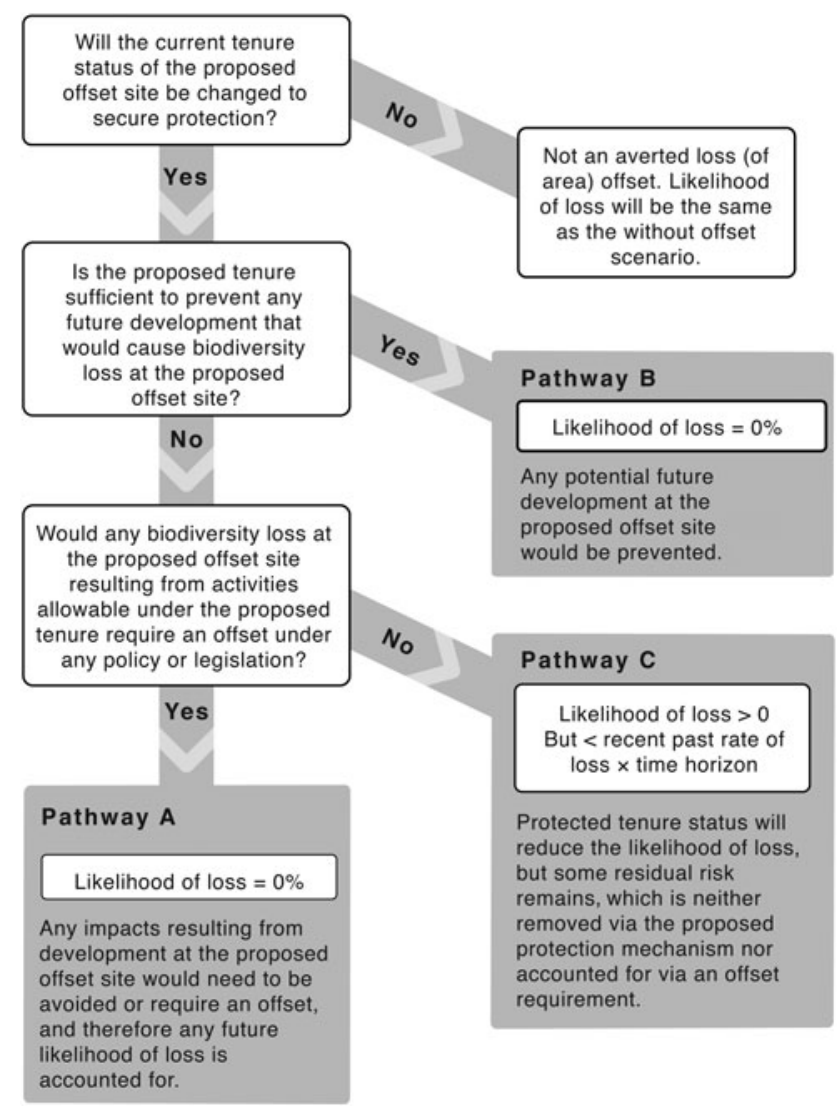

FIG. 3 A process for determining future likelihood of loss (total loss of area) under an offset scenario $\left(P_{o}\right)$. The time horizon is the period over which the outcome of the offset is being calculated (e.g. benefit achieved at 20 years).

trigger an offset requirement. In such situations, the likelihood of loss at the proposed offset site is considered to be greater than the calculated recent rates of loss. Pathway D, however, illustrates that in the absence of credible evidence that development will occur specifically at the proposed offset site, and where any unforeseen impacts would be type II impacts, it can be assumed that the site is subject to the same level of threat as other sites in the landscape. Therefore, the likelihood of loss can be derived using the calculated recent rates of loss without any adjustment.

\section{Estimating likelihood of loss under the offset scenario}

The pathways in Fig. 3 describe factors to take into account when estimating the likelihood of loss of a proposed offset site under an offset scenario, in which the site receives additional protection. In addition to the factors that need to be considered under the counterfactual scenario, a further important consideration is the strength of protection (e.g. through change in tenure) that will be placed on the site to avert future losses. 
Pathway A describes situations in which the proposed protection is insufficient to entirely prevent the loss of the site, for example when certain use rights override the protection mechanism. However, if the impacts caused by any such activity would themselves require an offset, the likelihood of loss is not elevated, and thus remains negligible (o\% in Fig. 3). For example, exploration for and extraction of mineral resources are permitted under several forms of legal land protection in Australia, but their impacts on listed threatened species often must be avoided or offset. We note, however, that impacts on offset projects will not always, or in all jurisdictions, be offset in compliance with policy (e.g. the impacted Kalagala offset for the Bujagali hydropower project in Uganda; Esmail, 2017).

Pathway B describes situations in which the proposed form of protection is sufficient to prevent loss of the site. In these cases, the proposed offset action (protecting the site) is sufficient to reduce the likelihood of loss (the magnitude of which is determined under the counterfactual scenario) to a negligible level.

Pathway C describes situations in which loss of the site would be neither prevented by the proposed protected tenure status nor likely to be subject to an offset requirement. In these situations, an appropriate likelihood of loss assumption would be greater than zero, but less than the calculated recent rates of loss at similar, unprotected sites. This acknowledges that the protection conferred on the site by the offset will reduce the likelihood of loss, but some residual risk remains.

To progress through the decision tree, our method requires landscape-scale assessment of recent rates of loss, and then site-scale evaluation of additional, localized influences on likelihood of loss.

\section{Step 1: Describing recent rates of loss at a landscape scale}

In the absence of other data, recent rates of loss calculated at a landscape scale can make a plausible and independently verifiable contribution to predicting future rates of loss at a proposed offset site within that same landscape (Maseyk et al., 2017). This assumption is made on the basis that sites within the same landscape are subject to similar anthropogenic influences. Although this may not hold true under certain circumstances, such as a change of regulations affecting vegetation removal (Evans, 2016; Rhodes et al., 2017; Simmons et al., 2018), it provides a useful starting point for estimating $P_{w o}$. If estimates do deviate from $P_{w o}$, additional evidence is required to support this. Recent work in Australia illustrates the implementation of this method, where it was used to estimate risk of forest loss (equivalent to likelihood of loss) across Australia by measuring change in forest extent resulting from human intervention within a recent 10-year period (2005-2014) using forest extent and change imagery (Maseyk et al., 2017). The change in forest extent was then used to calculate the annual rate of primary deforestation within local government areas across Australia, expressed as a proportion of the remaining forest extent. Finally, the mean annual rate of deforestation during 2005-2014 was calculated for each local government area (Fig. 4). These rates were multiplied by 20 (the Australian policy requires risk of loss to be calculated within a 20-year time horizon, referred to as 'foreseeable future') to estimate the risk of loss for each local government area. These risks of loss figures have been recommended as a basis for estimates required by the Australian Offsets Assessment Guide (Miller et al., 2015; Maseyk et al., 2017). Using remotely sensed land-cover data is an accepted and repeatable method by which to determine land-cover change in forest and woodland ecosystems. However, it has some limitations, including being less reliable at higher resolutions (e.g. property scale) and insufficiently sensitive to capture patterns of loss at low resolutions (e.g. country scale), and being less reliable for non-forest habitat types. Additional research should focus on understanding the spatial and temporal scales most useful for using past biodiversity losses to estimate future likelihood of loss, including situations in which assessment at a larger scale (e.g. local government area) may obscure heterogeneity within the area caused by factors such as soil type, production potential, or proximity to existing settlements or desirable areas for residential expansion. Future assessment of data on past loss rates should also be refined to exclude loss driven by development that would have triggered an offset requirement (type I impacts), which will also improve the accuracy of likelihood of loss estimates, particularly when concentrated activities such as urbanization can skew data when evaluated at larger scales. We also suggest that methods for identifying change in habitat types for which remotely sensed data are less readily available or accurate (e.g. habitat types dominated by non-woody or shortstature vegetation) are needed to improve this approach.

\section{Step 2: Consider any additional site-specific factors influencing likelihood of loss}

Once recent rates of loss at similar sites have been described, a site-specific assessment of likelihood of loss is required to ascertain (1) whether any additional factors that influence likelihood of loss are at play, and (2) whether activities in the wider landscape that contribute to loss are occurring, or are likely to occur, at the proposed offset site. If there is no evidence to suggest otherwise, it is possible to assume that a given offset site will be subject to the same rate of loss as other similar rates of loss in the landscape; however, there may be good reasons why such an assumption does not hold. Consequently, we suggest that conclusions and 


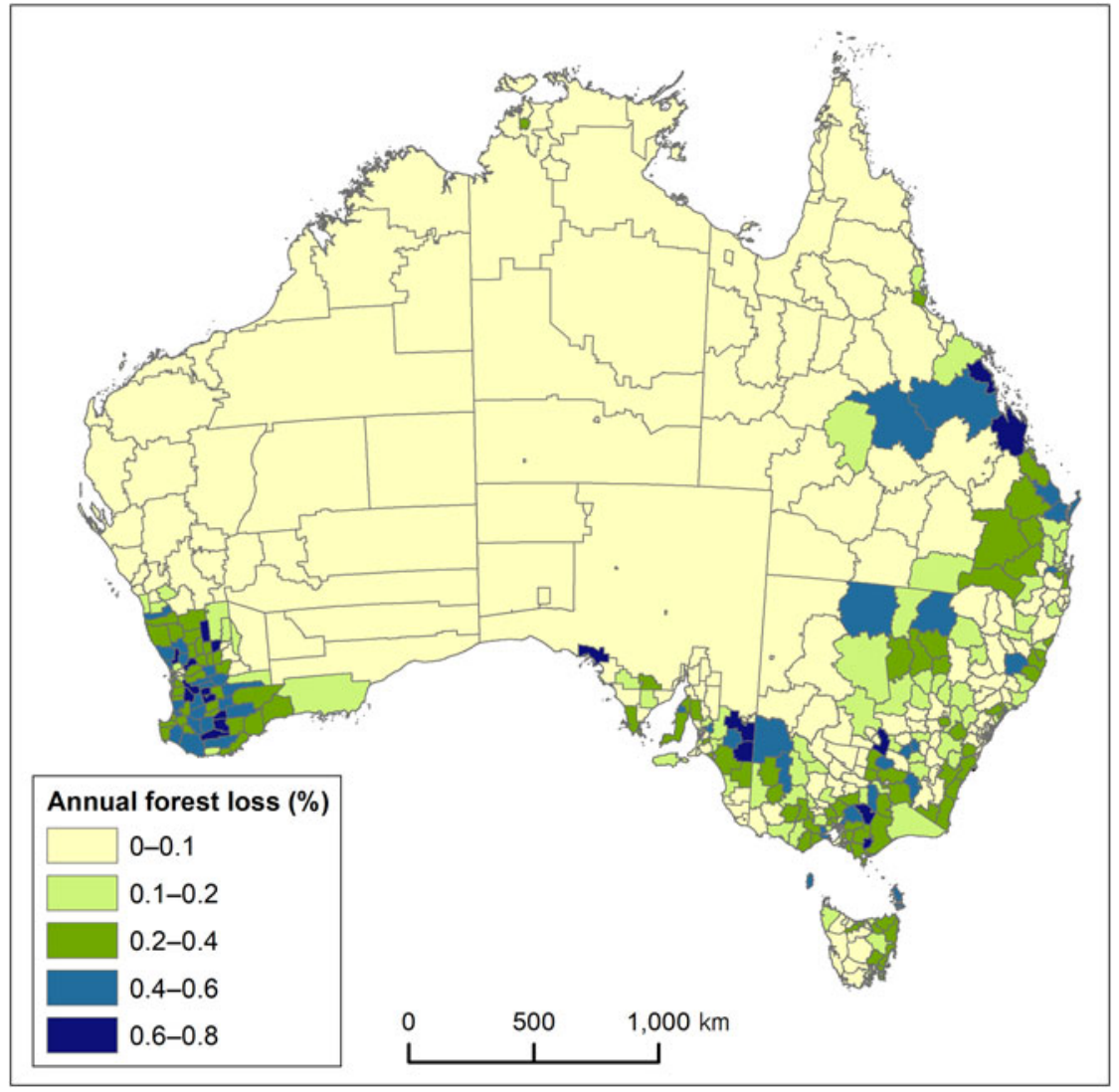

FIG. 4 Mean annual rate of forest loss during 2005-2014 within each local government area across Australia (adapted from Maseyk et al., 2017). These rates calculated from past deforestation rates are considerably lower than declines assumed in offset approaches in Australia (Maron et al., 2015). assumptions regarding likelihood of loss at a proposed offset site need to be supported with site-specific, credible, and robust evidence that is documented and made publicly available. In particular, if it has been determined that the likelihood of loss for a proposed offset site is greater than the background rate of loss, the evidence needs to demonstrate the likelihood of the proposed offset site being lost, and not just state that loss may occur (e.g. under current planning legislation and policy), or that it is known to occur at other sites.

\section{Discussion}

Biodiversity conservation requires the long-term maintenance and enhancement of both habitat extent and quality and this necessitates a combination of actions that avert loss of area, increase quality of existing biodiversity and reinstate lost biodiversity. The greatest offset gains will be secured by averting loss in circumstances where future threat is high, and defensibly estimated, and by increasing quality of existing biodiversity through both protection and management of habitat in accordance with clearly stated objectives for offset policies and conservation outcomes. It must also be acknowledged that obtaining no net loss outcomes by averting loss is relative to a baseline of decline (Maron et al., 2018), and real conservation gains can only be achieved through policies that are targeted at protection and restoration (Arlidge et al., 2018).

Here we propose a transparent, robust, and consistent method to improve estimation of likelihood of future loss of biodiversity at a site, which in turn will improve the accuracy of the estimated amount of biodiversity gain generated by an averted loss offset. For simplicity we focus only on averting loss of area and only one offset action, protection of the site. However, the basic logic presented here is also applicable to evaluating biodiversity gain by averting loss of condition. In particular, the emphasis on explicitly separating estimations for offset and counterfactual scenarios and differentiating between type I and type II impacts is universally relevant.

We also show that observed background rates of loss in forest extent in Australia during 2005-2014 are substantially lower than rates being used to estimate future likelihood of loss (Maseyk et al., 2017), or assumed within Australian biodiversity offset policies (Maron et al., 2015). It has been suggested that no net loss offsets based purely on averted loss are only likely to be acceptable to industry at ratios below 10:1 (Gibbons et al., 2016), which would equate to a counterfactual annual rate of biodiversity loss $\geq 6 \%$. As the highest mean annual rate of loss we recorded within a local government area was $<_{1} \%$, this underscores the very limited scope for no net loss to be achieved using only averted loss offsets. 
Many socio-political factors influence offset policies, design and implementation. Ratios are particularly prone to these influences in that politically acceptable multipliers are likely to be smaller than ecologically necessary (Bull et al., 2017). This results in decisions around multipliers resting on reasonable effort, rather than levels required to achieve no net loss (e.g. Carver \& Sullivan, 2017). In the context of averted loss offsets, this preference for acceptable levels of effort can translate into a willingness to accept unrealistic assumptions about future loss that support a smaller offset effort. Thus, methods such as the one proposed here, which employ more realistic assumptions about future loss, are necessary to counter the tendency to favour smaller offset requirements.

\section{Limitations of relying on protection actions to achieve biodiversity gains}

The use of protection actions to generate biodiversity gains as an offset for development impacts is common practice in some regions. Changing land tenure, in many places, may be perceived to be relatively straightforward, inexpensive, and quick compared to the complexities, uncertainties, expense and long timeframes associated with maintenance or enhancement activities. In addition, protection offsets such as land acquisition compared favourably to other offset types in terms of environmental outcomes in Western Australia (May et al., 2016). However, the amount of gain that can be credited to the offset action can only be calculated if likelihood of loss in absence of protection has also been estimated. The protection of 100 ha only equates to 100 ha offset gain if the land would otherwise have been cleared immediately. Although the action of protecting the site can carry greater certainty, and greater ease of implementation monitoring (e.g. land protected or not protected), the outcome remains uncertain because the counterfactual is uncertain. This illustrates the critical difference between an action occurring (e.g. Was the land procured? Were the trees planted?) and whether the chosen offset action is likely to generate the amount of gain anticipated (e.g. Was the estimated future loss averted?; Ferraro, 2009; Maron et al., 2013; Gibbons et al., 2016). Whereas the former is straightforward to measure, the latter can only ever be estimated, such as by examining trends in the surrounding landscape and extrapolating these trends to the site in question.

Furthermore, protection actions aimed at averting loss of area are often perceived to secure existing biodiversity values immediately (from the point at which the area is protected), apparently avoiding uncertainties associated with time lags between losses occurring and gains being generated. Thus, if there is a tangible threat to the persistence of that biodiversity into the future, averting loss can be seen as a more socially acceptable offset option than restoration offsets, where there is greater uncertainty that the anticipated gains will be achieved. However, immediate biodiversity gains are only generated where the likelihood of loss is high and expected loss is imminent. Typically, the likelihood that a site might be lost accrues gradually, and so the gains secured by a protection offset will also gradually accrue over time (Sonter et al., 2017). Prediction becomes progressively more difficult as the time horizon increases (e.g. 10 vs 50 years). Thus, defining a time horizon is important and needs to be both realistic in terms of capturing future likelihood of loss, yet relevant to policy timeframes, and meaningful for monitoring ecological change in response to offset actions.

The method proposed here does not explicitly attempt to account for non-compliance with protection agreements or the likelihood of illegal activities occurring within the offset site, and also assumes that offset sites would be protected in perpetuity (i.e. protection status would not be downgraded or removed in the future). If the likelihood of illegal damage at a potential offset site was considered too high even with the protection that could be afforded, then alternative offset sites should be sought. It should be noted, however, that the lack of permanence for offset sites as a result of expected non-compliance or protected area downgrading, downsizing and degazettement events (Golden Kroner et al., 2019) further reduces the expected biodiversity gain delivered by averted loss offsets.

Although we focus on likelihood of complete loss of a proposed offset site, the same logic can be applied to other situations (such as future loss of condition) by substituting protection actions for alternative actions targeted to prevent further habitat degradation. This will pose the same practical challenges mentioned here (determining the appropriate scale at which to calculate past loss and the inherent difficulties in predicting the future). However, biodiversity condition data are often lacking and trends in change of condition are often difficult to determine. This can be resolved to some degree by predictive modelling, or informed by structured expert judgement (Hemming et al., 2018).

\section{Using recent background rates of loss to inform future estimates}

In many situations, relying on past background rates of loss (e.g. the previous 10 years) can be a plausible predictor of future rates of loss, or at least a good starting point. This method introduces consistency and transparency, and is less open to misuse than unguided site-by-site estimates. However, it may not always be reasonable to use past rates of loss to inform future likelihoods of loss, such as when fluctuating commodity prices or economic shocks have driven land-use change at a faster rate than experienced in the recent past. Reliably predicting such future events is extremely difficult and therefore past rates are often a 
reasonable proxy, although in cases of marked changes in rates of loss over time such guidance is less useful. In such situations, a more relevant time period may be used as a baseline, or a selection of plausible trends could be specified (e.g. Bull et al., 2015) and a conservative assumption made, although this carries risks that estimates of gain will be artificially inflated. Furthermore, although we used a linear mean calculation in our case study, a geometric mean may be more appropriate to reflect the non-linear nature of ecological dynamics (Buschke, 2017).

An ideal approach would be to develop a predictive model that accounts for multiple drivers of potential loss (e.g. distance from roads and settlements, productive capability of underlying soils, land tenure), as has been applied elsewhere (Sonter et al., 2014, 2017). However, such modelling requires substantial resourcing and agency capacity that would not be feasible in many cases. Relying instead on past background rates of loss is an improvement on much of current practice, which tends to be ad hoc and less than transparent.

Given the limitations of relying on past rates of loss alone to inform future loss estimates, any assumptions should be explicit, and if over time these assumptions are proven incorrect, the loss-gain calculations underpinning the offset design need to be revisited. This highlights the need for ongoing outcome monitoring of both offset sites and other sites in the landscape that act as controls, so that the impact of averted loss measures can be estimated, and the counterfactual assumptions evaluated over time.

\section{Incorporating site-specific influences on likelihood of loss estimates}

Care is required to ensure that socio-political pressures do not have undue influence in situations where site-specific considerations are incorporated into estimates of likelihood of loss. Another risk is that a requirement for site-specific evidence at a particular offset site could create an incentive to generate threats to claim a greater amount of biodiversity gain using averted loss offsets. This could lead to overinflated likelihood of loss and set precedents for unrealistic likelihood of loss estimates (Maseyk et al., 2017). To prevent this, declarations of intended development should be subject to adequate scrutiny to ensure they are genuine, and not merely obtained to inflate likelihood of loss.

A further site-specific issue relevant to estimating future likelihood of loss is the chance that averting loss at a specific site will cause so-called leakage, meaning that the biodiversity loss may be prevented at the offset site but shifted elsewhere and thus not actually averted. The likelihood of leakage occurring is dependent on the policy framework relevant to the site in question (Maron et al., 2018); i.e. whether the activity that is being shifted would trigger an offset requirement at the third site or not. If leakage is a real risk, this would confound estimates of gains generated using averted loss offsets. Caution is thus necessary when relying solely on averted loss offsets.

\section{Conclusion}

The ability and likelihood of offset actions to deliver biodiversity gains successfully are shrouded in uncertainty, and failures are common (Quigley \& Harper, 2006; Burgin, 2010; May et al., 2016). Quantifying the gain generated by averted loss offsets relies on the accuracy of assumptions about likelihood of loss, the uncertainty of which cannot be resolved in most cases. This inherent uncertainty in predicting the future is common to all offset actions, but is exacerbated in averted loss offsets as the variation in gain estimates is most affected by the counterfactual scenario, which is never observed and therefore can never be proven. However, improving the reasoning process for arriving at estimates of benefit from offsets, and making assumptions transparent is critical for ensuring averted loss offsets do not in fact entrench and accelerate biodiversity losses (Maron et al., 2015).

Acknowledgements This research was funded by the Australian Government's National Environmental Science Program through the Threatened Species Recovery Hub Project 5.1 'Better offsets for threatened species'. MM is supported by Australian Research Council (ARC) Future Fellowship FT140100516. AG is supported by an Australian Research Council Discovery Project (DP150103122).

Author contributions Development of the guidance to the Australian Department of the Environment and Energy (the basis of this work): FM, ME, MM; conception: all authors; writing: FM; further development and revisions: all authors.

\section{Conflict of interest None.}

Ethical standards This research abided by the Oryx guidelines on ethical standards.

\section{References}

Arlidge, W.N., Bull, J.W., Addison, P.F., Burgass, M.J., Gianuca, D., Gorham, T.M. et al. (2018) A global mitigation hierarchy for nature conservation. Bioscience, 68, 336-347.

Australian Government (2018) EPBC Act Environmental Offsets Policy. environment.gov.au/epbc/publications/epbc-actenvironmental-offsets-policy [accessed 16 April 2018].

Bull, J., Singh, N., Suttle, K., By kova, E. \& Milner-Gulland, E.J. (2015) Creating a frame of reference for conservation interventions. Land Use Policy, 49, 273-286.

Bull, J.W., Lloyd, S.P. \& Strange, N. (2017) Implementation gap between the theory and practice of biodiversity offset multipliers. Conservation Letters, 10, 656-669.

Burgin, S. (2010) 'Mitigation banks' for wetland conservation: a major success or an unmitigated disaster? Wetlands Ecology and Management, 18, 49-55. 
Buschke, F.T. (2017) Biodiversity trajectories and the time needed to achieve no net loss through averted-loss biodiversity offsets. Ecological Modelling, 352, 54-57.

Carver, L. \& Sullivan, S. (2017) How economic contexts shape calculations of yield in biodiversity offsetting. Conservation Biology, 31, 1053-1065.

Department of Environment Land Water and Planning (2017) Native Vegetation Gain Scoring Manual Version 2. Victoria State Government, Melbourne, Australia.

Esmail, N. (2017) Stakeholder and Institutional Analysis: Achieving No Net Loss for Communities and Biodiversity in Uganda. Wild Business Ltd. for University of Oxford. Wild Business Ltd., London, UK.

Evans, M.C. (2016) Deforestation in Australia: drivers, trends and policy responses. Pacific Conservation Biology, 22, 130-150.

Ferraro, P.J. (2008) Asymmetric information and contract design for payments for environmental services. Ecological Economics, $65,810-821$.

Ferraro, P.J. (2009) Counterfactual thinking and impact evaluation in environmental policy. New Directions for Evaluation, 2009, 75-84.

Ferraro, P.J. \& Pattanayak, S.K. (2006) Money for nothing? A cal for empirical evaluation of biodiversity conservation investments. PLOS Biology, 4, e105.

Gibbons, P., Evans, M.C., Maron, M., Gordon, A., Le Roux, D., VON HASE, A. et al. (2016) A loss-gain calculator for biodiversity offsets and the circumstances in which no net loss is feasible. Conservation Letters, 9, 252-259.

Golden Kroner, R.E., Qin, S., Cook, C.N., Krithivasan, R., Pack, S.M., Bonilla, O.D. et al. (2019) The uncertain future of protected lands and waters. Science, 364, 881-886.

Gordon, A., Langford, W.T., Todd, J.A., White, M.D., Mullerworth, D.W. \& Bekessy, S.A. (2011) Assessing the impacts of biodiversity offset policies. Environmental Modelling \& Software, 26, 1481-1488.

Gordon, A., Bull, J.W., Wilcox, C. \& Maron, M. (2015) Perverse incentives risk undermining biodiversity offset policies. Journal of Applied Ecology, 52, 532-537.

Hemming, V., Burgman, M.A., Hanea, A.M., McBride, M.F. \& WinTLE, B.C. (2018) A practical guide to structured expert elicitation using the IDEA protocol. Methods in Ecology and Evolution, 9, 169-180.

IUCN (2016) WCC-2016-Res-059-EN IUCN Policy on Biodiversity Offsets. iucn.org/theme/business-and-biodiversity/our-work/ business-approaches-and-tools/biodiversity-offsets [accessed 17 August 2018].

Kahneman, D., Knetsch, J.L. \& Thaler, R.H. (1991) Anomalies: the endowment effect, loss aversion, and status quo bias. Journal of Economic Perspectives, 5, 193-206.

Maron, M., Rhodes, J.R. \& Gibbons, P. (2013) Calculating the benefit of conservation actions. Conservation Letters, 6, 359-367.

Maron, M., Bull, J.W., Evans, M.C. \& Gordon, A. (2015) Locking in loss: baselines of decline in Australian biodiversity offset policies. Biological Conservation, 192, 504-512.

Maron, M., Ives, C.D., Kujala, H., Bull, J.W., Maseyk, F.J.F., Bekessy, S. et al. (2016) Taming a wicked problem: resolving controversies in biodiversity offsetting. Bioscience, 66, 489-498.

Maron, M., Brownlie, S., Bull, J.W., Evans, M.C., von Hase, A., Quétier, F. et al. (2018) The many meanings of no net loss in environmental policy. Nature Sustainability, 1, 19-27.

Masey , F.J.F., Barea, L.P., Stephens, R.T.T., Possingham, H.P., Dutson, G. \& Maron, M. (2016) A disaggregated biodiversity offset accounting model to improve estimation of ecological equivalency and no net loss. Biological Conservation, 204, 322-332.

Maseyk, F.J.F., Evans, M.C. \& Maron, M. (2017) Guidance for Deriving 'Risk of Loss' Estimates When Evaluating Biodiversity Offset Proposals Under the EPBC Act. Report to the National Environmental Science Programme Department of the Environment and Energy. Centre of Biodiversity and Conservation Science, The University of Queensland, Brisbane, Australia.

May, J., Новbs, R.J. \& Valentine, L.E. (2016) Are offsets effective? An evaluation of recent environmental offsets in Western Australia. Biological Conservation, 206, 249-257.

Miller, K.L., Trezise, J.A., Kraus, S., Dripps, K., Evans, M.C., Gibions, P. et al. (2015) The development of the Australian environmental offsets policy: from theory to practice. Environmental Conservation, 42, 306-314.

Montenegro, S.S., Walschburger, T., Sarmiento, J.L. \& Tamayo, J.C.G. (2012) Manual for Allocating Offsets for Loss of Biodiversity. Ministry of Environment and Sustainable Development, Bogotá, Colombia.

Quigley, J.T. \& Harper, D.J. (2006) Effectiveness of fish habitat compensation in Canada in achieving no net loss. Environmental Management, 37, 351-366.

Rhodes, J.R., Cattarino, L., Seabrook, L. \& Maron, M. (2017) Assessing the effectiveness of regulation to protect threatened forests. Biological Conservation, 216, 33-42.

Ruhl, J. \& SalZman, J. (2011) Gaming the past: the theory and practice of historic baselines in the administrative state. Vanderbilt Law Review, 64, 1-57.

Simmons, B.A., Law, E.A., Marcos-Martinez, R., Bryan, B.A., McAlpine, C. \& Wilson, K.A. (2018) Spatial and temporal patterns of land clearing during policy change. Land Use Policy, 75, 399-410.

Sonter, L., Barrett, D. \& Soares-Filho, B. (2014) Offsetting the impacts of mining to achieve no net loss of native vegetation. Conservation Biology, 28, 1068-1076.

Sonter, L., Tomsett, N., Wu, D. \& Maron, M. (2017) Biodiversity offsetting in dynamic landscapes: influence of regulatory context and counterfactual assumptions on achievement of no net loss. Biological Conservation, 206, 314-319.

Sunstein, C.R. (2003) Terrorism and probability neglect. Journal of Risk and Uncertainty, 26, 121-136.

Temple, H., Anstee, S., Ekstrom, J., Pilgrim, J. \& Rabenantoandro, J. (2012) Forecasting the Path Towards a Net Positive Impact on Biodiversity for Rio Tinto QMM. IUCN and Rio Tinto, Gland, Switzerland.

The Biodiversity Consultancy (TBC) \& Flora \& Fauna International (FFI) (2012) Biodiversity Offsets Strategy for the Oyu Tolgoi Project. Unpublished draft report of The Biodiversity Consultancy Ltd. and Fauna \& Flora International, Cambridge, UK.

The State of New South Wales \& The Office of Environment and Heritage (2014) BioBanking Assessment Methodology. Office of Environment and Heritage for the New South Wales Government, Sydney, Australia.

The State of Queensland (2014) Queensland Environmental Offsets Policy Version 1.1. Department of Environment and Heritage Protection, Brisbane, Australia.

Tversky, A. \& Kahneman, D. (1974) Judgment under uncertainty: heuristics and biases. Science, 185, 1124-1131.

Wende, W., Tucker, G., Quétier, F., Rayment, M. \& Darbi, M. (eds) (2018) Biodiversity Offsets-European Perspectives on No Net Loss of Biodiversity and Ecosystem Services. Springer International Publishing, Basel, Switzerland. 